\title{
Blue Ocean Strategy di Industri Perhotelan
}

\author{
Kadek Linda Kusnita \\ Harper Kuta Hotel \\ lindakusnita93@gmail.com
}

\begin{abstract}
This research is intended to know the marketing carried out by Harper Kuta Hotel to get out of the Red Ocean Marketing carried out in the hospitality industry has implemented a red ocean zone which in all hotels uses the same marketing strategy, so marketing is offered in marketing. This study uses qualitative methods and uses four blue ocean frameworks that explain the strategies that must be corrected and corrected. Data collection uses interview techniques from each resource person. The final goal of this research is to learn the advantages possessed by Harper Kuta Hotel, so that they can choose the right strategy and have innovation.
\end{abstract}

Keywords: Blue Ocean Strategy; Marketing Strategy

\begin{abstract}
ABSTRAK
Penelitian ini bertujuan untuk mengatahui pemasaran yang di lakukan oleh Hotel Harper Kuta untuk keluar dari Red Ocean. Pemasaran yang dilakukan di industri perhotelan sudah memasuki zona red ocean, dimana semua hotel menggunakan strategi pemasaran yang sama, maka di perlukan inovasi dalam pemasaran. Penelitian ini menggunakan metode kualitatif dan menggunakan four framework blue ocean yang menjelaskan dari strategi yang sudah ada yang harus di kurangi dan di perbaiki. Pengumpulan data menggunakan teknik wawancara dari masing masing narasumber. Tujuan akhir dari penelitian ini adalah untuk mengetahui kelebihan yang dimiliki Hotel Harper Kuta, sehingga dapat memilih strategi yang sesuai dan memiliki inovasi.
\end{abstract}

Keywords : Blue Ocean Strategy; Strategi Pemasaran 


\section{PENDAHULUAN}

Di dewasa ini, perkembangan teknologi sangatlah pesat. Dunia teknologi bergerak sangat cepat sehingga setiap perubahan mempercepat perubahan berikutnya, selain itu perkembangan teknologi secara tidak langsung mengubah pemasaran secara radikal. Dunia pemasaran saat ini berkutat dengan transformasi digital yang sedang berkembang (Darma, 2018).

Mckinsey dalam buku Marketing 4.0 philip Kotler mengatakan bahwa inovasi teratas yang memberikan dampak ekonomi paling signifikan, termasuk internet ponsel, automasi pekerjaan pengetahuan, internet of things dan lain-lain. Beberapa sector yang sangat berkembang seiring perkembangan teknologi yaitu, Sektor ritel, Sektor Transportasi, Pendidikan, Kesehatan dan pariwisata.

Teknologi ini membantu mengembangkan sektor-sektor ekonomi, seperti sektor ritel dengan e-commerce, transportasi dengan kendaraan automatis, pendidikan dengan aneka kursus online, kesehatan, sampai interaksi sosial melalui media social dan Sektor pariwisata dengan pemasaran Digital melalui flatform. Dalam periode transisi dan adaptasi menuju ekonomi digital sangat dibutuhkan pendekatan pemasaran yang baru untuk memandu pemasaran dalam mengantisipasi dan mengungkit teknologi disruptif (Widani dkk., 2019).

Marketing 4.0 adalah pemasaran yang memadukan antara interaksi online dan offline. Marketing 4.0 adalah pergeseran dari pemasaran marketing 1.0 yang pemasarannya berorientasi pada produk ke pemasarannya, marketing 2.0 adalah pemasaran yang berorientasi pada pelanggan dan marketing 3.0 adalah pemasaran yang berorientasi pada manusia. Sebagaimana yang di jelaskan pada buku Marketing 3.0 Hermawan kertajaya bahwa di era marketing 3.0 pelanggan bertansformasi sebagai manusia seutuhnya. Di era ekonomi digital, interaksi digital saja tidaklah cukup. Kenyataannya, justru di saat dunia online yang semakin berkembang, sentuhan offline menjadi titik diferensiasi yang kuat. Berkembangnya marketing 4.0 ini menyebabkan semua sector ekonomi harus mengubah strategi yang digunakan untuk memenangkan persaingan. Sektor pariwisata, adalah salah satu sector yang merasakan baik dan buruknya perkembangan marketing 4.0 (didukung juga hasil penelitian dari Dewi dan Darma, 2019).

Bali adalah wilayah pariwisata yang terkenal di Dunia. Selain terkenal dengan keindahan alam dan adat istiadatnya yang sangat kental, Bali juga memiliki daya tarik sendiri yaitu keramahan yang di miliki oleh orang Bali sendiri (Bali dan Darma, 2019). Menurut 
laporan Badan Pusat Statistik Provinsi Bali Tahun 2017 mencatat 10 Negara wisatawan yang memberi kontribusi terbesar bagi pariwisata Bali, yaitu :

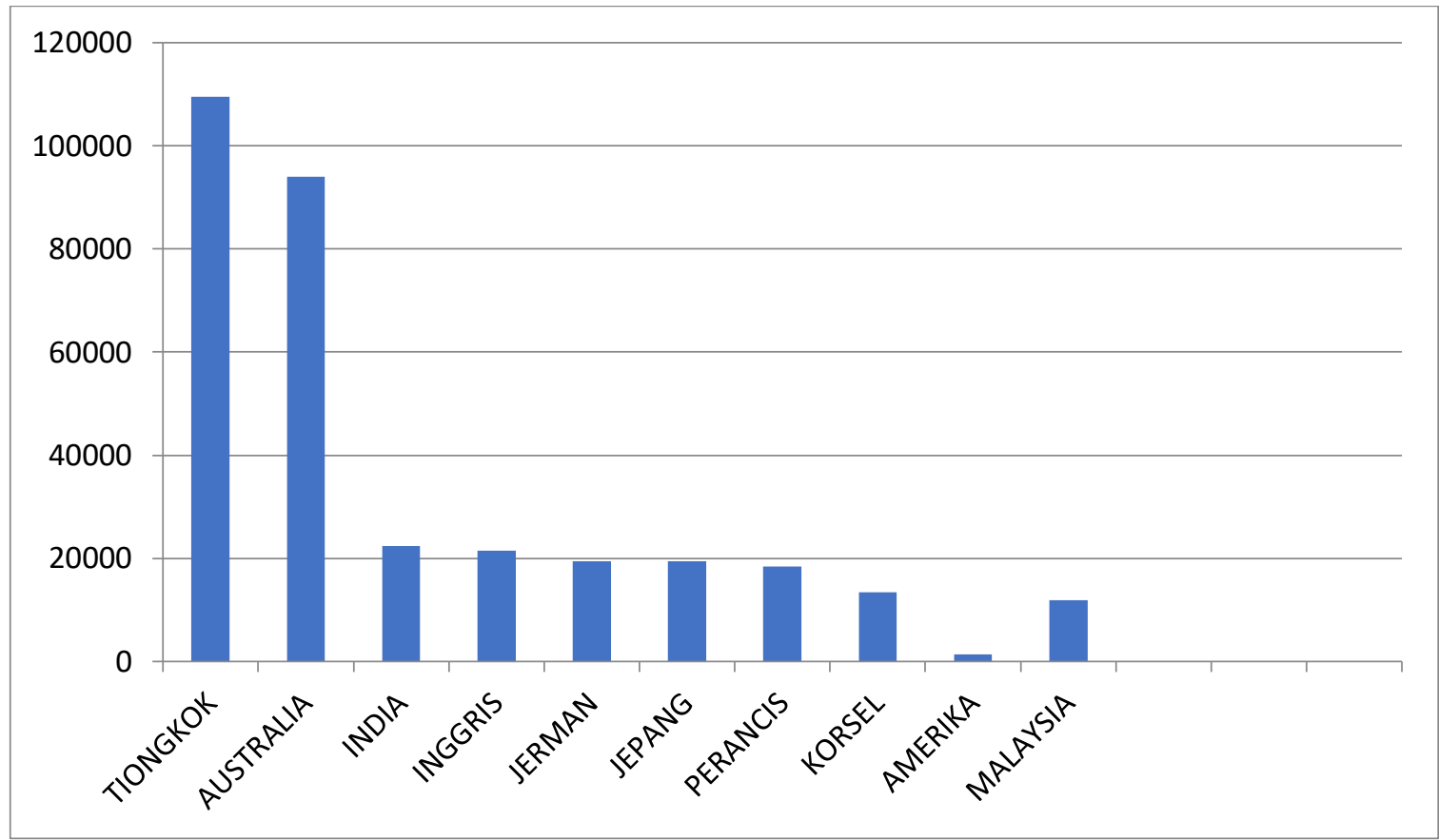

Gambar 1.1 Statistik Wisatawan yang berkunjung 2017

Dimana menurut statistik diatas tercatat 10 negara yang member kontribusi bagi pariwisata di Bali. Diurutan pertama Negara tiongkok yang datang untuk mengunjungi Bali sebanyak 109,534 ribu orang, Australia dengan jumlah pengunjung sebesar 93,992 ribu orang, India dengan jumlah 22,449 ribu orang, Inggris dengan jumlah pengunjung sebesar 21,466 orang, Jerman dengan jumlah pengunjung sebesar 19,460 orang, Jepang dengan jumlah pengunjung sebesar 19,449 orang, Perancis dengan jumlah pengunjung sebesar 18,423 orang , Korea selatan dengan jumlah pengunjung sebesar 13, 416 orang, Amerika serikat dengan jumlah pengunjung sebesar 11,324 orang dan Malaysia dengan jumlah pengunjung 11,892 orang. Tidak hanya memiliki daya tarik pemandangan dan attitude orang Bali yang baik, tetapi Bali juga sudah dianggap sebagai Second Home oleh wisatawan Asing.

Meningkatnya kunjungan ke Bali, maka sangat di perlukannya fasilitas penginapan yang dapat mendukung perkembangan pariwisata. Menurut UUD NO. 10 Tahun 2009 dimana setiap daerah yang memiliki potensi pariwisata dapat dibina dengan baik dan berbagai macam kegiatan wisata didukung berbagai fasilitas serta layanan yang disediakan oleh masyarakat, pengusaha, dan pemerintah daerah. Selain itu, sektor pariwisata merupakan tulang punggung perekonomian Bali. Kehadiran teknologi informasi sebagai alat bantu pemasaran sangat menentukan keberhasilan pemasaran jasa penginapan di era digital (Darma, 2018) Seperti 
radio, televisi dan jaringan komputer atau internet. Internet adalah media sejuta umat yang dapat diakses tanpa batasan waktu, internet menawarkan kecepatan, efisiensi untuk bertukar informasi tanpa harus ketempat tujuan.

Pada industry perhotelan, internet mempunyai peranan penting menghubungkan pelanggan dan hotel agar terjadi pertukaran informasi dan transaksi bisnis, dan mempengaruhi perbaikan kinerja hotel melalui pengurangan biaya distribusi, peningkatan pendapatan dan perbaikan akses ke pasar (gratzer et al, 2002; Yudiastra dan Darma, 2015). Dengan berkembangnya teknologi telah mendorong terjadinya perubahan pola perilaku konsumen yang menyebabkan industri perhotelan harus mengganti strategi pemasaran yang dimiliki.

Suatu kemampuan mengalahkan pesaing adalah hal terpenting, dimana kompetitor biasanya memberikan tawaran fitur produk yang seragam, sama, dan semua saling memperebutkan pasar yang juga sama. Maka mudah dibayangkan yang terjadi adalah pertarungan sengit, yaitu medan persaingan diperebutkan oleh para pemain yang menawarkan keseragaman produk dan pendekatan atau yang lebih di kenal dengan red ocean strategy yang sedang dialami oleh perhotelan saat ini. Produk dan pelayanan yang di tawarkan memiliki kesamaan dan membidik pasar yang sama. Ciri-ciri red ocean yang terjadi dalam perhotelan adalah karena yang terjadi pada pasar tersebut, permintaan lebih sedikit dari pada penawaran. Akibatnya persaingan dengan kompetitor menjadi sangat ketat dan bisa saja antar pesaing saling menghancurkan. Demand yang berkurang dikarenakan dengan banyak berdirinya hotelhotel baru yang menyediakan layanan dengan harga yang rendah (Handika dkk., 2018).

Tuntutan yang harus di lalui hotel-hotel di Bali adalah menciptakan pasarnya sendiri, sehingga persaingan tidak lagi relevan untuk di bicarakan. Keluar dari red ocean, mengharuskan hotel-hotel memiliki keunikan dan ciri khas yang dimiliki tidak saja pada karakteristik hotel melainkan dengan strategi pemasaran yang di gunakan. Kondisi saat ini yang dihadapi oleh perusahaan yang bergerak pada penyedia jasa penginapan adalah bagaimana merubah strategi pemasaran offline mengarah ke pemasaran online untuk mengoptimalkan tingkat hunian kamar (Kusnadi dan Darma, 2018) Salah satu cara meningkatkan kemampuan perusahaan serta menciptakan segmen pasar tersendiri adalah dengan memberikan inovasi nilai/value innovation (Kim dan Mauborgne, 2006; Katen dan Darma, 2017).

Legian merupakan wilayah yang wajib dikunjungi oleh wisatawan yang datang ke Bali. Legian terkenal dengan icon monument bom Bali dan Banyaknya hiburan malam serta artshop di sekitar jalan legian membuat para pengusaha penginapan berlomba membangun hotel di jalan legian. Mulai dari melati hingga Hotel kelas 4star pun didirikan sekitarnya. 
Persaingan pun semakin ketat, karena adanya competitor yang tidak seimbang selain itu adanya perang harga yang di berikan oleh hotel-hotel yang memiliki kelas yang sama demi mengejar occoupancy. Segmen pasar yang di masuki oleh hotel-hotel di legian cendrung sama dan menggunkan strategy yang sama.

Menurut kotler (2005), strategi pemasaran adalah penerapan strategi pemasaran yang tepat dapat memberikan dampak jangka panjang positif bagi perusahaan, terutama dalam hal mempertahankan pelanggan, penguasaan pangsa pasar yang ada, serta menghadapi persaingan. Tujuannya adalah untuk mampu bersaing dalam keadaan dan apabila strategi pemasaran yang diterapkan oleh perusahaan dapat berjalan dengan baik dan lancer maka akan dapat meningkatkan volume penjualan jasa diperusahaan jasa hotel.

Berdasarkan fenomena diatas peneliti merasa perlu dilakukan penelitian bagaimanakah Startegi pemasaran yang di lakukan dengan pendekatan Blue Ocean strategy agar mampu menciptakan pasar yang baru.

Peneliti Hermanto (2011) dengan judul penelitian Implementation Blue Ocean Strategy at Group Wings yang menghasilkan : bahwa untuk dapat menjadi 'berbeda' dari yang lain, tidak harus selalu dengan berusaha menciptakan suatu ruang pasar baru. Hal itu bisa dimulai dari value innovation, atau hanya sekedar memberikan value added pada produk/jasa yang sudah ada. Memberikan plus value pada sebuah produk caranya bisa bermacammacam. Bisa dengan menambah features atau benefits dari produk-produk yang sudah ada, bisa dengan menawarkan harga yang lebih rendah untuk benefits yang sama (atau bahkan lebih) dengan produk yang sudah lebih dulu beredar di pasar. Cara lain lagi, untuk menjadi berbeda dan kemudian berenang-renang sendirian dengan penuh kemenangan di Blue Ocean, juga bisa didapat dari pricing-strategy. Dengan mengefesienkan segala macam proses produksi, otomatis dapat menawarkan harga yang lebih rendah dari pesaing.

Peneliti Umar Chadiq (2009) dengan judul penelitian Implementasi strategi Blue Ocean untuk mencapai kinerja perushaan yang kompetitif menghasilkan : Beberapa faktor yang dapat mendorong dan berpengaruh terhadap pengimplementasian strategi samudra biru, yaitu:

1. Melakukan rekonstruksi batasan pasar agar berpengaruh positif terhadap implementasi strategi blue ocean.

2. Lebih fokus pada gambaran besar kompetisi supaya bisa berpengaruh positif terhadap implementasi strategi blue ocean.

3. Memikirkan jangkauan permintaan supaya berpengaruh secara baik terhadap implementasi strategi blue ocean. 
4. Menghilangkan rintangan organisasi yang kemungkinan bisa terjadi supaya dapat mengimplementasikan strategi blue ocean.

5. Melakukan integrasi dalam pengambilan keputusan strategis supaya terjadi koordinasi antar sub sistemdalam perusahaan.

6. Implementasi dari strategi blue ocean memungkinkan untuk melahirkan suatu kondisi kinerja yang tinggi dan sulit ditiru. Para manajer perusahaan harus berani meninggalkan paradigma lama yaitu bersaing sekuat tenaga dalam samudra merah persaingan seperti itu akan berdarah-darah (dengan menghabiskan semua sumber daya perusahaan) dan tidak akan menghasilkan kinerja bisnis yang optimal. Sebaliknya, menerima paradigma baru yaitu memakai sumber daya untuk penciptaan samudra biru yang melampaui persaingan dan akan membawa perusahaannya pada kinerja bisnis tidak tertandingi dan kompetitif dengan kunggulannya yang dimiliki serta bisa bertahan dalam jangka waktu lama.

Peneliti Kevin Ryan (2013) dengan judul penelitian Analisa strategi bersaing PT. Mitra Agro Lestari Bersama yang menghasilkan : Strategi yang digunakan perusahaan untuk menuju Samudra Biru:

1. Integrasi kebelakang Pembelihan lahan untuk pengelolahan bahan baku yang berguna untuk mengurangi persaingan dalam hal pengambilan bahan baku.

2. Pengembangan produk Pengembangan produk berupa pengolahan kulit kacang menjadi CNSL, pembuatan mete goreng, dan pengembangan kacang mete organic.

3. Cost leadership Penggunaan mesin sebagai proses produksi memungkinkan untuk pengurangan biaya dalam perusahaan. Hal ini menjadi hal utama agar perusahaan dapat memiliki keunggulan dalam hal jual dari perusahaan pesaing.

Peneliti dengan judul Perumusan Blue Ocean Strategy sebagai strategi bersaing perusahaan keluarga PT. Belirang Kalisari yang menghasilkan : strategi yang dipakai PT. BelKa saat ini termasuk strategi differentiation. Strategi ini ditandai dengan ciri produk yang mengutamakan kualitas produk yang baik dan keunikan produk melalui formulasi bahan baku dan bahan pendukung yang menjadikan produknya berbeda dengan produk lain. Dari sisi harga, PT. BelKa menawarkan harga yang lebih tinggi dibandingkan pesaingnya, karena perusahaan tidak bermain pada harga rendah, melainkan menekankan harga pada manfaat yang di dapat konsumen. Dari sisi pemilihan pasar, perusahaan berkecimpung pada B2B sektor dimana hubungan dengan perusahaan distributor dan retailer menjadi penting. Selanjutnya dari sisi pemasaran, PT. BelKa melakukan teknik pemasaran dengan pendekatan personal melalui 
promosi-promosi dan event-event yang ditujukan kepada distributor, retailer, dan konsumen akhir. Pemasaran ini dianggap tungguh karena pendekatan tidak hanya dilakukan kepada konsumen langsungnya (distributor) melainkan kepada konsumen akhirnya juga untuk menciptakan demand. Strategi bersaing PT. Belirang Kalisari bila dirumuskan menggunakan blue ocean stategy akan membentuk suatu ide baru. Dengan menggunakan blue ocean stategy, utilitas/ manfaat yang dapat diciptakan adalah faktor kemudahan bagi konsumen. Faktor yang ditawarkan berbentuk produk dengan isi/konten yang sama dengan produk lama yang sudah dilarutkan dengan air (konsumen tidak perlu mencampurkan sendiri) dikemas didalam spayer mini agar konsumen dapat langsung menggunakannya secara instan.

Peneliti sarah Melinda yang berjudul Penerapan Blue Ocean Strategy dalam usaha memasuki pasar internasional (study pada UMKM Jilbab Bulak balik) menyatakan bahwa : Analisis lingkungan perusahaan melalui pengamatan internal dan eksternal menghasilkan Matrix Grand Strategy yang sesuai dengan Kanvas Strategi pada perumusan alat blue ocean. Formulasi blue ocean strategy pada Pricilla tetap pada visinya untuk konsisten mengangkat nilai sosial. Selain itu tim Research \& Development dan agen menjadi bagian utama untuk menciptakan inovasi nilai. Hal ini juga mampu membuat perusahaan memperbarui blue ocean strategy-nya dan menjauh dari persaingan Red Ocean. Eksekusi blue ocean strategy pada Pricilla pada praktiknya mampu mengatasi hambatan. 


\section{Kerangka Konseptual}

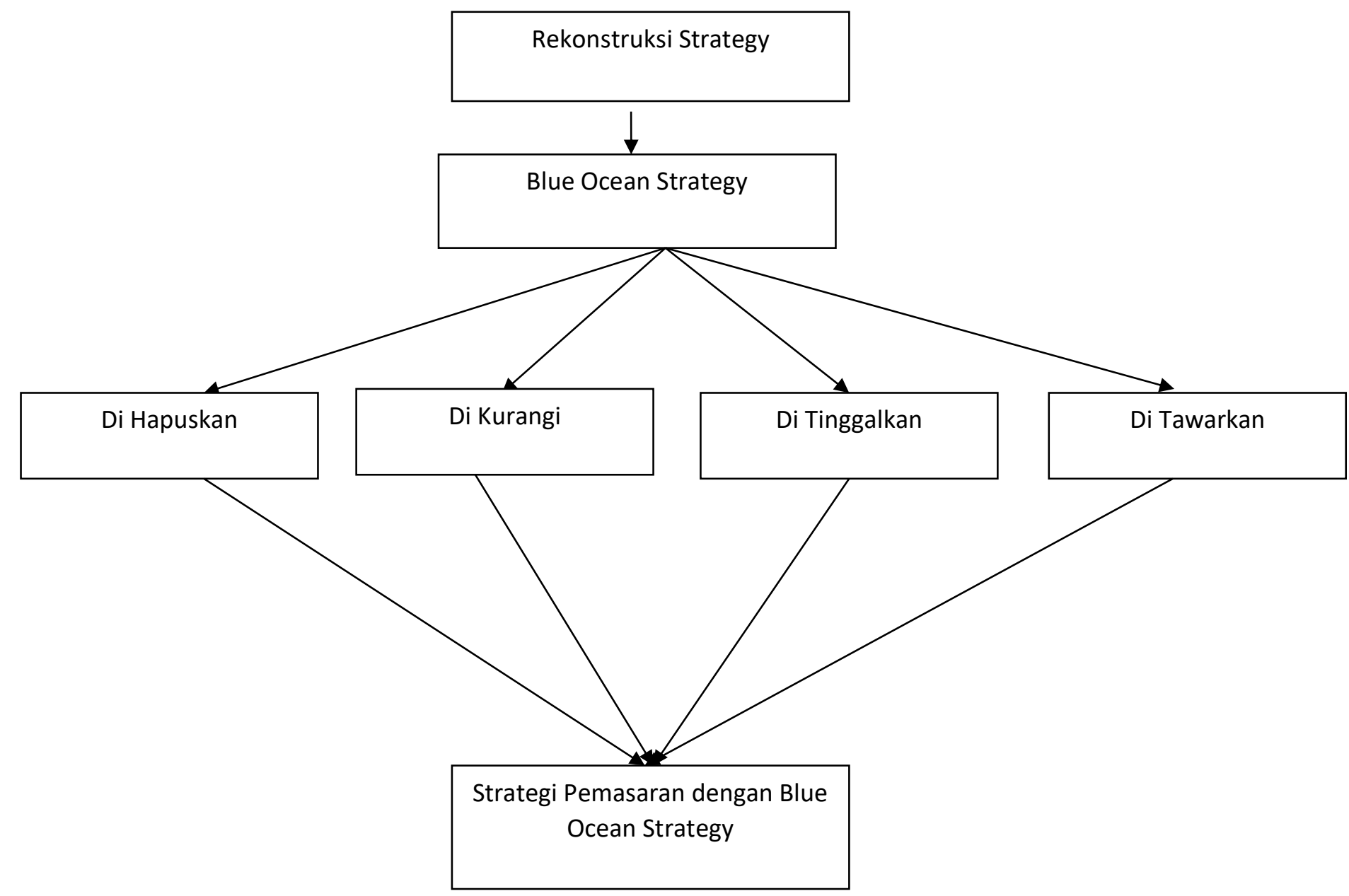

\section{METODE PENELITIAN}

Penelitian ini mengambil Hotel Harper Kuta sebagai sumber data. Harper kuta adalah Salah satu hotel yang di managed oleh management archiperlago imternational. Berdiri sejak 2013, hotel ini menerapkan konsep modern dan tradisional. Terletak di jalan Legian. Penelitian menggunakan metode pendekatan kualitatif dengan metode analisis deskriptif yang dapat diartikan sebagai metode penelitian yang berlandaskan pada filsafat enterpretif digunakan untuk meneliti pada kondisi obyek yang alamiah, (sebagai lawannya adalah eksperimen) dimana peneliti sebagai instrumen kunci, teknik pengumpulan data dilakukan secara trianggulasi (gabungan), analisis data bersifat induktif atau kualitatif, dan hasil penelitian kualitatif lebih menekankan makna dari pada generalisasi.(Sugiyono, 2013)

Dalam penelitian ini teknik sampling yang digunakan yaitu purposive sampling. Menurut Sugiyono (2016) purposive sampling adalah teknik pengambilan sampel sumber data 
dengan pertimbangan tertentu. Alasan menggunakan teknik Purposive Sampling adalah karena tidak semua sampel memiliki kriteria yang sesuai dengan fenomena yang diteliti. Oleh karena itu, penulis memilih teknik Purposive Sampling yang menetapkan pertimbangan-pertimbangan atau kriteria-kriteria tertentu yang harus dipenuhi oleh sampel-sampel yang digunakan dalam penelitian ini.

Penulis juga mengumpulkan data dengan melakukan wawanara dengan para informan yang berhubungan langsung dengan perusahaan. Face to face interview (wawancara berhadaphadapan) dilakukan terhadap enam partisipan yang diharapkan penulis bisa mendapatkan data yang solid.

\section{PEMBAHASAN}

Prinsip blue ocean strategy yaitu melakukan inovasi nilai dengan meningkatkan nilai manfaat sekaligus mengurangi biaya. Kinerja empat langkap yang diusulkan dalam penelitian ini diharapkan dapat mengakomodir apa yang menjadi prinsip blue ocean strategy. Inovasi nilai dengan meningkatkan nilai manfaat ditempuh dengan cara memaksimalkan potensi yang sudah ada dan membangun suatu hal yang baru. Peningkatan potensi yang telah ada sebelumnya adalah dengan cara sebagai berikut.

1) Menjaga kualitas website

Website yang telah ada sebaiknya di-refresh secara periodik baik dari segi tampilan maupun keamanannya. Desain komunikasi visual sebaiknya dapat dibuat lebih komperehensif dengan menampilkan seluruh aspek terbaik yang dimiliki oleh Harper Kuta. Tampilan yang komperehensif ii sebaiknya juga tetap menimbulkan dampak komunikatif dua arah antara pihak hotel dan konsumen. Keamanan website perlu ditingkatkan untuk menjaga agar web tidak mudah dirusak oleh pihak lain sehingga terjadi kebocoran data.

2) Kualitas SDM pemasaran SDM pemasaran internal perlu ditingkatkan keterampilannya dalam menjual produk yang dimiliki oleh Harper Kuta. Peningkatan dapat dilakukan dengan pengiriman karyawan ke berbagai seminar maupun pelatihan yang fokus pada pemasaran bisnis hospitality.

Agen pemasaran eksternal sebaiknya bukan hanya mampu menjual produk, namun juga pengetahuan akan produk (product knowledge) dapat ditingkatkan. Pengetahuan yang dimaksud adalah terkait dengan prinsip blue ocean strategy yang wajib 
menghasilkan inovasi-inovasi baru. Agen wajib mengetahui dan memahami inovasi yang ada dari Harper Kuta.

3) Penggunaan public figure

Wabah penggunaan media sosial untuk mendulang pendapatan pada saat ini sudah sangat kuatnya. Karena itu penggunaan youtuber dan selebgram sebagai ujung tombak pemasaran pada era 4.0 adalah sebuah konsekwensi. Fasilitasi keinginan mereka untuk berkreasi jelas sangat diperlukan baik pada saat ini maupun di masa depan.

Inovasi yang sebaiknya dapat dibangun adalah sebagai berikut.

1) Membangun sistem pemasaran digital ter-update sesuai perkembangan 4.0 Penyediaan perangkat digital yang sesuai untuk mengakomodir perkembangan 4.0 jelas sangat diperlukan. Perangkat digital ini sebaiknya mempunyai spesifikasi yang dapat men-support perkembangan sistem yang diperlukan dalam pemasaran produk Harper Kuta.

Sistem pemasaran dengan pendekatan digital tentunya berbeda dengan sistem konvensional. Perubahan cepat dan sering tidak terduga harus dapat disikapi secara tepat sehingga keunggulan Harper Kuta tetap dapat dijaga.

2) Media bagi youtuber dan selebgram berkreasi

Media sosial khususnya youtube dan selebram menjadi media yang paling diminati untuk memperoleh pendapatan yang besar. Kondisi ini perlu disikapi Harper Kuta dengan membuat brand baru bahwa Harper Kuta adalah tempat para youtuber dan selebgram berkarya. Fasilitasi lokasi maupun fasilitas pendukung bahkan sponsorship tentunya menarik minat para kreator dari seluruh dunia hadir di Harper Kuta.

Peningkatan dan penciptaan inovasi baru tentunya akan memunculkan biaya baru. Karena itu perlu dilakukan tindakan penghapusan dan pengurangan. Penghapusan yang dimaksud adalah sebagai berikut.

1) Penjualan melalui travel agent yang tidak potensial.

2) Promosi melalui media cetak dan elektronik.

Pengurangan dilakukan pada dua biaya yaitu biaya promosi dan iklan serta biaya peningkatan kualitas pelayanan. 


\section{PENUTUP}

Inovasi nilai dengan meningkatkan nilai manfaat ditempuh dengan cara memaksimalkan potensi yang sudah ada dan membangun suatu hal yang baru. Peningkatan potensi yang telah ada sebelumnya adalah dengan beberapa cara. Cara pertama, yaitu menjaga kualitas website.Website yang telah ada sebaiknya di-refresh secara periodik baik dari segi tampilan maupun keamanannya.Desain komunikasi visual sebaiknya dapat dibuat lebih komperehensif dengan menampilkan seluruh aspek terbaik yang dimiliki oleh Harper Kuta.Tampilan yang komperehensif ii sebaiknya juga tetap menimbulkan dampak komunikatif dua arah antara pihak hotel dan konsumen. Keamanan website perlu ditingkatkan untuk menjaga agar web tidak mudah dirusak oleh pihak lain sehingga terjadi kebocoran data. Cara kedua, yaitu Kualitas SDM pemasaran. SDM pemasaran internal perlu ditingkatkan keterampilannya dalam menjual produk yang dimiliki oleh Harper Kuta.Peningkatan dapat dilakukan dengan pengiriman karyawan ke berbagai seminar maupun pelatihan yang fokus pada pemasaran bisnis hospitality. Agen pemasaran eksternal sebaiknya bukan hanya mampu menjual produk, namun juga pengetahuan akan produk (product knowledge) dapat ditingkatkan. Pengetahuan yang dimaksud adalah terkait dengan prinsip blue ocean strategy yang wajib menghasilkan inovasi-inovasi baru.Agen wajib mengetahui dan memahami inovasi yang ada dari Harper Kuta. Cara Ketiga, yaitu Penggunaan public figure. Wabah penggunaan media sosial untuk mendulang pendapatan pada saat ini sudah sangat kuatnya.Karena itu penggunaan youtuber dan selebgram sebagai ujung tombak pemasaran pada era 4.0 adalah sebuah konsekwensi. Fasilitasi keinginan mereka untuk berkreasi jelas sangat diperlukan baik pada saat ini maupun di masa depan. 


\section{DAFTAR PUSTAKA}

Ananda, A., and Subawa, N.S. (2018). Strategi Pemasaran Akibat Perubahan Consumer Behaviour, Jurnal Manajemen dan Bisnis, 15 (2).

Adicandra, A. (2017). Strategi Pengembangan Bisnis Berdasarkan Blue Ocean Strategy Pada PT. Inti Lautan Fajar Abadi, Agora, 5 (1).

Bali, I.N.A.P., and Darma, G.S. (2019). Menguji Kesiapan Pengelolaan Desa Berbasis Manajemen Modern Guna Menghadapi Era Revolusi Industri 4.0, Jurnal Manajemen \& Bisnis, 16 (2): 1-13.

Blanchard, O. (2011). Social Media ROI: Managing and Measuring Social Media Efforts in Your Organization. Pearson Education, Inc.

Capra, F. (2009). The Hidden Connections Strategi Sistemik Melawan Kapitalisme Baru. Bandung: Jala Sutera.

Chadhiq, U. (2009). Implementasi Strategi Blue Ocean Untuk Mencapai Kinerja Perusahaan Yang Kompetitif.

Darma, G.S. (2006). Mobile Marketing: Sebuah Strategi Keunggulan Bersaing Online. Denpasar: Undiknas Press.

Darma, G.S. (2018). Seuntai Pesan, Menjawab Zaman. Indonesia: Pustaka Larasan Press.

Dewi, M.V.K., and Darma, G.S. (2019). The Role of Marketing \& Competitive Intelligence In Industrial Revolution 4.0, Jurnal Manajemen \& Bisnis, 16 (1): 1-12.

Dewi, C.R., and Darma, G.S. (2014). Website Usability, Satisfaction, Loyalty, Security Perception, Trust, and Word of Mouth in e-Commerce Business, Jurnal Manajemen \& Bisnis, 11 (2): 1-30.

Handika, M.R., Maradona, A.F., and Darma, G.S. (2018). Strategi Pemasaran Bisnis Kuliner Menggunakan Influencer Melalui Media Sosial, Jurnal Manajemen \& Bisnis, 15 (2): 188-199.

Hamdani, M. (2018). Analisis Penerapan Red Ocean Strategy dan Blue Ocean Strategy Menggunakan Skema Hapuskan-Kurangi-Tingkatkan-Ciptakan, Kanvas Strategi dan Indeks Samudra Biru pada Coffee Shop di Medan.

Hasibuan, Z.A. (2017). Model Perencanaan Strategis Sistem Informasi Pada Industri Penyiaran Televisi Dengan Pendekatan Blue Ocean Strategy Dan Balanced Scorecard.

Kanten, I.K., and Darma, G.S. (2017). Consumer Behaviour, Marketing Strategy, Customer Satisfaction, and Business Performance, Jurnal Manajemen \& Bisnis, 14 (2): 143-165. 
Kho, M.C.K., dan Indriyani, R. (2014). Perumusan Blue Ocean Strategy Sebagai Strategi Bersaing Pada Perusahaan Keluarga Cv. Gama Abadi, Agora, 2 (1).

Kim, W.C., dan Mauborgne, R. (2014). Bluce Ocean Strategy. Edisi Ketiga. Jakarta: PT. Serambi Ilmu Semesta.

Kotler, P., \& Keller, K. L. (2009). Marketing Management (13th ed.). Pearson International Edition.

Odiljon. (2012). Blue ocean strategy : analisis of the sectors thas has benefited and a glance into which other sectors may benefit from applying this strategy.

Prathama, K. R. (2013). Analisa Strategi Bersaing PT. Mitra Agr Lestari Bersama, Agora, 1 (3).

Septarini. (2014). Perumusan Startegi Samudra Biru KT-Gongsin.

Soyomukti, N. (2008). Pendidikan Berspektif Globalisasi. Yogyakarta: AR-RUUZ Media.

Widani, N.M., Abiyasa, A.P., Darma, G.S., and Maradona, A.F. (2019). Menguji Ketajaman Implementasi E-Commerce Dalam Penjualan Kamar Hotel di Bali, Jurnal Manajemen \& Bisnis, 16 (2): 79-98.

Yudiastra, P.P., and Darma, G.S. (2015). Pengaruh Penggunaan Teknologi Informasi, Disiplin Kerja, Insentif, Turnover Terhadap Kinerja Pegawai, Jurnal Manajemen \& Bisnis, 12 (1): $156-172$.

Yuniastuti, V. (2015). Blue Ocean Strategy Evaluation in Green Property Implementation Of Pt. Harmoni Properti Indonesia. 